\title{
The Role of Transdisciplinary Studies in the reform of the Engineering Cur- riculum: A Case Study
}

\section{Dr. John Heywood, Trinity College Dublin, The University of Dublin}

Dr Heywood is professorial Emeritus of trinity College Dublin-The University of Dublin. he is a Fellow of ASEEE and Life Sen Member IEEE and author of Engineering Education: research and development in Curriculum and Instruction..

\section{Dr. Mani Mina, Iowa State University}

Mani Mina is with the department of Electrical and Computer Engineering at Iowa State University. He has been working on better understanding of students' learning and issues of technological and engineering philosophy and literacy. In particular how such literacy and competency are reflected in curricular and student activities. In addition he is active in research of engineering education and new focuses on engineering pedagogy. 


\title{
The Role of Transdisciplinary Courses in the Reform of the Engineering Curriculum. A Case Study.
}

\begin{abstract}
The case study presented in this paper is a description of a blended transdisciplinary Small Private On-Line Course (SPOC) conducted by one of the authors for a selected group of faculty and doctoral students brought together by the co-author. The aim of the course was to enable the participants to reflect on who and what we are as individuals and engineers in a society that is becoming increasingly complex. It necessarily integrated knowledge from several disciplines and in consequence is transdisciplinary.

The paper begins with a brief discussion of transdisciplinarity and interdisciplinarity. It is followed by a section on the transdisciplinary nature of engineering literacy.

A major problem for those who wish to design interdisciplinary or transdisciplinary courses is the lack of suitable introductory texts and the unwillingness of publishers to publish texts that fall outside the scope of the traditional curriculum and its numbered course. In this case, the SPOC (Small Private On-Line Course) was blended: the text of the course was made available (accumulatively) in parts at the time of each of eleven video presentations (Skype), which were presented a few days in advance of a seminar/discussion (Skype).

The course, its origins, aims and presentation are described, and its limitations and potential considered in the light of current discussions on the integration of engineering and liberal education, and developments in the role of technological and engineering literacy.
\end{abstract}

Abstract 225 words.

Key words. Blended, Humanities, SPOC, Transdisiplinary.

\section{Transdisciplinarity and Interdisciplinarity}

In the 1960's a number of novel degree structures emerged in Europe. Of special interest to this text was the idea of interdisciplinary institutions that would function around a particular concept. For example an institute was established for the sociology and politics of work. Its purpose was to establish a theory of work ${ }^{1}$. The Organisation for Economic Co-operation and Development (OECD) schematized this approach as follows:

1. "A single complex problem.

2. Disciplines noteworthy for their viewpoints

(a) The variety of their viewpoints.

(b) The possibility that the fields overlap.

(c) The fact that no single discipline covers the entire problem. 
3. Different solutions all of which are necessarily incomplete depending on the viewpoint of each discipline

(a) A synthesis.

(b) A single solution".

At the time Heywood ${ }^{2}$ described this approach as "transdisciplinary" and the complex problem "engineering". He described a course that he ran for undergraduate engineers which linked the behavioural sciences (including economics) and humanities in a common framework. Its purpose was to introduce engineering students to their role in industry and society. It differed from the OECD definition in that it was not problem based. This course was broad and introductory and designed only to meet the first stage of Whitehead's cycle of rhythm in learning ${ }^{3-4}$. Heywood subsequently developed the management dimensions of this course to a basic course in management for experienced teachers as part of their continuing professional development that resulted in a published text in 1989 that was totally revised in $2009^{5-6}$.

In so far as engineering was concerned the idea of transdisciplinarity was resurrected by Ertas et al in 2003 who argued that it was the direction the engineering curriculum should take ${ }^{7}$. Following Kozmetsky ${ }^{8}$ they defined transdisciplinarity "as the integrated use of [the] tools, techniques and methods from various disciplines. Such thinking forces one to think across beyond and through the academic disciplines to encompass all types of knowledge about an idea, issue or subjects". It may be argued that the problems faced by engineers will almost always require of them the application of ideas gleaned from many areas of knowledge. The design of courses to prepare engineers for the reality of engineering is difficult and requires radically new approaches. Problem based learning pioneered by Woods in engineering ${ }^{9-10}$ and project based learning schemes ${ }^{11}$ may go some way toward meeting this need.

Ertas et $\mathrm{al}^{12}$ argued that neither textbooks nor university organizations made the development of such courses easy. Heywood also found that students used to unitary approaches had difficulty with this kind of study. There was no reason to believe that such problems had been solved (see below). He also found that publishers resisted publishing interdisciplinary books and it was not until 1989 that he was able to publish a book based on half the original course ${ }^{5}$. Dyer and Schmalzel ${ }^{13}$ also reported great difficulty in finding textbooks that were structured around a "just-in-time" approach that would be suitable for project work.

The course to be described below may be seen as a development of Heywood's early work. It is appreciated that in the US other definitions of integration and interdisciplinarity are used and a substantial discussion of these will be found in Heywood $(2005)^{14}$ (see also Fogarty, $1993^{15}$ ). However, there are two points that need to be made.

First, the idea of inter-disciplinary study in the British Isles is mostly associated with courses in which students study two subjects throughout the period of study to the major (honours) level. With rare exceptions it seems that academics do not welcome such studies but would prefer the student to study their own subject and their own subject alone. A study in which one of us was involved found there was no give and take. Each teacher required the students 
to do more or less the same course that they would have to have taken had they pursued it as a single entity. Notwithstanding the heavy study load imposed on the students there is little evidence that the courses were interdisciplinary in the sense that studies in the one subject informed studies in the other and vice-versa. A basic requirement of inter-disciplinarity of this kind would be a common set of goals.

Second, this point is related to another major objection that is made against the development of interdisciplinary courses or the addition of material that is outside of the focus of the applications of science to engineering problems is that it takes away teaching time that is badly needed to cover the engineering syllabus. But this stems from a naive tabula rasa view of teaching which is to the effect that a student must know all there is to know to about a subject before they can be released into the world. But such is the explosion of knowledge this eventuality would in any case be an impossibility. Rather the purpose of education should be to develop the key concepts and principles that will enable students to improve their skills of transfer. It also stems from a lack of understanding of what it is that engineers do and the complexity of the problems they have to solve.

\section{The transdisciplinary nature of technological and engineering literacy}

Recent papers presented at meeting of the Technological and Engineering literacy/Philosophy Division of the American Society for Engineering Education have in their discussions of curricular to service these literacies shown that engineering is a multi-faceted activity that requires engineers to have knowledge and skills that extend well beyond those traditionally associated with the engineering curricular. The reflection of the engineering curricular within programs of engineering and technological literacy necessarily requires a transdisciplinary approach to their teaching, and this is implied by the definitions of these literacies described by Krupczak et $\mathrm{al}^{16}$.

Krupczak et al in their justification of the development of programs in engineering and technological literacy write that since "engineering concepts are pervasive in decision making within industry, government, education, health care" every citizen should be exposed in their education "to the central ideas and principles underlying our technological society". They find support for this view in the National Academy of Engineering's reports on "Technically Speaking: Why all Americans Need to Know more about Technology", and "Changing the Conversation. Messages for Improving Public Understanding of Engineering".

No wonder then that a variety of courses in the guise of technological literacy have been introduced in the United States, or that there is much discourse about their content arising from the meaning that technology has for different groups of people. For example, a key issue for engineering policy makers is whether "technology" and "engineering" are synonymous "concepts". That this should be an issue is not surprising for, while there seems to be a public stereotype of the "technologist", a term that is often linked with "scientist" there seems to be no great perception of what it is that engineers do, or of the significance of the term "engineering". This may be regarded as harmful to the image of the engineer and 
consequently to the engineer's status in society. So a key question for engineers is where does engineering literacy fit into the muddle that has become technological literacy?

The Krupczak et al, ${ }^{17}$ presented several different ways of distinguishing between engineering and technological literacy. In one of them they argued that "engineering literacy is viewed as having a focus directed more toward the process of creating technological or systems." In contrast "technological literacy includes a broader view of products or results of the engineering process as well as the relation between technology and society". Krupzcak et al acknowledge that the "extent to which engineering and technological literacy form a subset of each other remains a topic for future discussion and investigation". On the basis of a process/product view of the issue Krupczak et al argue that a person who is technologically literate would have a "knowledge or ability to design, analyze or otherwise create the constituent parts of the....", and they give the example of the motor car.

They point out that in spite of the fact that "technology can be viewed as identifiable things that result from engineering or related work" and should therefore "include some knowledge of these concepts, systems and processes" the "term engineering is not treated systematically by any of the technological literacy standards" that have been written in the United States.

The implications for the curriculum are profound. At one extreme, content arises from consideration of the impact of technology on society and individuals in particular, and at the other end of the spectrum, it arises from the needs of non-engineers to deal with engineers and engineering in their everyday activities which on the one hand requires some knowledge of engineering science of the type most recently described by Krupczak (2014 - private communication), and on the other hand and understanding of how people behave. Given this scenario it is possible to envisage two (or more) entirely different programs in technological and engineering literacy. The question arises as to how these two might be linked in order to generate a common understanding of what it is to be engineering and technologically literate.

Inspection of the model in Exhibit 1 shows that it conflates both dimensions of literacy. Its perspective combines both a product/process and broad view of the two literacies. Clearly, the technologies (following Krupczak et al) that are the products of engineering, interact at all levels of society. This can be seen from the influence of electro-mechanical devices in the kitchen and the impact they have had on families, or at a societal level, as for example the concern that communities have for processes like fracking which enable large quantities of gas to be extracted from shale. At the micro-level changes in kitchen technology or for that matter electronics in the home are adapted to without much thought. Not so when a community is faced with fracking. While cell (mobile) phones were quickly accepted some communities reacted unfavourably to the systems antennas because of fears of cancer. To persuade communities engineering explanations for the acceptance of the technology, which they will be expected to take on trust, will be given. For them to make a rational decision they will have to have some knowledge of risk and some understanding of the engineering together with an ability to synthesize the two. In a word, they will need to be engineering and technologically literate. 


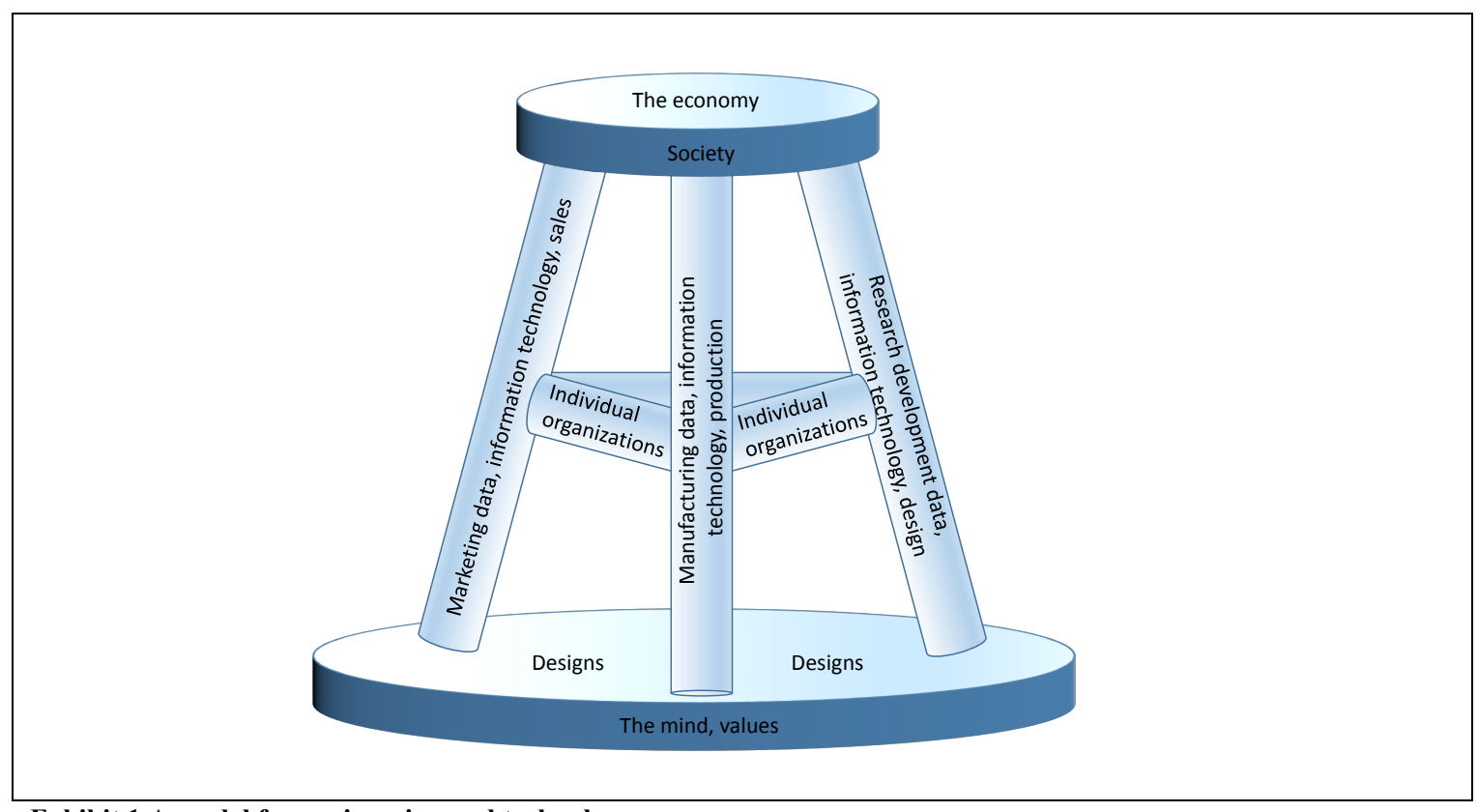

Exhibit 1 A model for engineering and technology

But the model is also indicative of the interactions that engineers must make and the languages they must learn to speak. The original model assumed that design was inclusive ${ }^{18}$ which seems to be a reflection of the engineering as the application of science model. This has been rectified in this version. But as Bucciarelli ${ }^{19-20}$ has pointed out design is a social process: how engineers participate in this process must be central to the understanding that technologically and engineering literate persons, let alone engineering students should have. Studies of engineers at work over a forty period support this view and show the need for what have come to be known as the "soft" skills. Heywood ${ }^{21}$ interpreted a study of engineers at work $^{22}$ to show the importance of the informal organization, the need for skills of persuasion, and the need that each person in the organization has for some degree of management skill. Hutton and Lawrence ${ }^{23}$ showed important cultural differences in the emphasis placed by German and British project engineers on the technical and the managerial aspects of work. A qualitative study by Vinck $^{24}$ showed the way social interactions contributed to the technical work of a mechanical engineer, and studies by Trevelyan ${ }^{25}$ during the last decade have shown the key role that "technical liaison" plays in the work of engineers. How engineers relate to other people is as much part of their value system as it is of their personality. Their philosophy of life is as important as their philosophy of engineering. It was this proposition that occupied the authors when they discussed the engineering curriculum and the literacies associated with it. It is clear is that the solving of complex engineering problems requires knowledge and skill in a variety of domains and the problem is how to develop that knowledge and skill within a heavily content driven curriculum. The course described below was directed at the human side of engineering. Mani Mina begins with a description of the origins and beginning of the course. 


\section{Origins of the course and the method of approach (Mani Mina)}

In the second semester of 2013 I was teaching the first class of Electrical Engineering (EE185). I had for some time been using student reflections to monitor their experience and provide them with a way to self evaluate their progress. I thought John Heywood would be a great person to bring as a guest to the class (via Skype) and for him to engage with the students. In the hope they would benefit from his experience and vision. Since freshman engineering students are highly motivated and want to know more about engineering, and what engineering is all about, it is always helpful to bring experts who can relate to them, talk with them, and hopefully inspire them. This is what I hoped would happen when they met with John They would meet a well a person of considerable experience in engineering, teaching, and education, who continues to actively participate in productive transformational work. The students were very surprised that such a person would be willing to answer their questions and be so interested in their ideas and thoughts.

A week before the meetings, I introduced John and his ideas and writings to the class. For that week in EE185 we discussed who John is and students read about him by reading his memories of 50 years of being in IEEE (on the IEEE History website). The students then created a set of questions for him to answer. The questions were sent to John a week before the meeting. On the day of the meeting, John was our guest via Skype and answered these and other questions by conversing with the students. The students of EE185 not only liked the session but also kept asking to have more similar sessions. In particular they wanted to have more sessions with John. After the first time, when they had got to know him better, they thought they could ask better questions. It seemed that they would benefit from another session in order to ask more questions, reflect on them, and think more deeply about what the experience did for them. I was not able to offer them a second session at that time but it is clear from their comments that there was a need for a second session so I planned to do this on another occasion.

The session with the freshman students was very successful, and since students loved it so much I thought it would be even better if we could engage higher-level students. Therefore, I agreed with John that he would conduct a seminar class of a few sessions with higher level and graduate students to see where it would take us. We would be in a position to judge audience response and decide whether to continue. John considered that we could bring the self, the person as an agent into the discussion and help the participants realize how to create their own journey in critical thinking, personal philosophy and pedagogy. Eventually, he decided to create a few discussion essays that would help the students and selected group of faculty to debate, think, discuss, and appreciate the role of engineering reflection, philosophy and pedagogy in engineering education.

At the beginning the series was intended for undergraduates. However, the more I investigated the situation the more I realized that interest amongst seniors, graduates, and faculty was much greater than I anticipated. For example one of the graduate students decided that this could have a great impact and he would become involved. This he did and he patiently taped every session and posted them on the website for all the participants (and 
others unable to attend who had expressed an interest in the course) to follow it so as to try and get the participants to work together in the hope of creating more in-depth discussion (see below). Brief details of the journeys are shown in Exhibit 2.

\section{Toward a new SPOC (Mani Mina)}

Since I am a faculty member of Electrical Engineering in the Electromagnetic area, I created a class for Fall 2013 called EE510M. The class was officially (according to the Iowa State University catalog) a special topic class with the following title "EE510M: Special topics on Electromagnetism." John mentioned that fifty or more years ago he worked on ionospheric research in industry, this may fit! While this was a real stretch of the imagination and regulations it was the only way that we could have a class to work on in the time that we had for our disposal. After the class was created I invited students and colleagues to participate. In order to be more descriptive about the seminar class we decided to adapt the title to "Critical Reflections on Engineering and Engineering Pedagogy".

The eleven Seminars were called journeys. As indicated above, each journey was captured on Skype by John Pritchard, a doctoral student attending the course. He recorded and

1. "It all depends on what you mean by..." (Focused on the meanings that engineers bring to their work with an introduction to the series).

2. "Thinking about Thinking"

3. "Things are not always what they seem" (An exploration of perception and learning).

4. "Meaning. True of False; Real or Imagined". (An exploration of constructivism and realism)

5. "From Perception to Self Perception and a Little Management En-Route". (About what people bring to their work and what organizations bring to them and the affect of structures on those relationships).

6. "Sharing Problems. Living in Communities

7. "Thinking about making a Good Engineer Possible".

8. "Aspiration in Engineering Ethics"

9. "Preparing for the future: Individuals and Organizations".

10. "Changing Us: Changing Society".

11. "Journey's End: A New beginning?

Exhibit 2. The 11 Journeys. Each exploration occupied between fifteen and twenty minutes. To be published by Morgan and Claypool together with the substantial notes that arose from the discussions.

directed the sessions and when they were edited they were posted them on websites that he created. Copies of the scripts were also made available so a participant could choose to view the Skype recording or read the script or use both. Then on Friday's we met with Heywood on Skype for a one hour session in which we debated with him the journey of the particular week. The sessions would start with questions and comments by the participants. Some of the questions were created prior to the session and emailed to John and the others were asked and discussed during the sessions.

Based on the discussions, the suggestions, the interactions, and the feedback, from the participants, John modified the journeys, added items, clarified points, and included some of the participants' points of view and contributions. A revised script was prepared and circulated. 


\section{Evaluation (Mani Mina)}

Those participating in the course divided into three groups:

1. Those who would attend the live sessions that constituted undergraduate and graduate students (from US and international perspectives) from electrical and computer engineering. In addition we also had faculty of Engineering, English, Rhetoric, and Physics attending the seminar class.

2. Those who followed the reading and activities within the campus of Iowa State University. This group included some of the members of the office of Dean of engineering including Associate Deans. In addition, we had a number of faculty and graduate students in engineering, sciences, English, philosophy who were following our activities via our website.

3. Finally interested national and international colleagues and friends including some of members of Technological and Engineering Literacy and philosophy of Engineering Division of ASEE and others also followed some of the activities also via our website.

We received reflections, critiques, and ideas from many of our caring and kind colleagues and student participants. Our colleagues and students patiently helped us think and rethink the activities and discussions. The Journeys reflect the feedback from the attendees and patrons who were kind enough to communicate with us during the progress of the project as well as after the completion as a part of ongoing critique and discussions. In particular we are very thankful to our special colleagues and friends in ASEE Technological and Engineering Literacy and Philosophy of Engineering Division including Professors Alan Cheville at Bucknell University and John Krupczak at Hope College.

The class was very successful as judged by the feedback given. In addition I received requests to organize more seminar series of this kind. The engagement of the participants and continuation of support, and requests for more of this kind of activity showed that our efforts were valued and need to continue in many forms. The class became an effective vehicle for all to reflect and think more deeply about their beliefs and perspectives in their field and its relationship to their education. Finally, it helped participants engage in the development of their personal "philosophy". We began the class with the title of "Critical Reflections on Engineering and Engineering pedagogy," and somewhere during the first half of the seminar it became "Critical Reflections on Engineering, Engineering Pedagogy, and Philosophy." Despite the fact that this does not seem to be a great change, the inclusion of philosophy in the title reflected the type of discussion that the participants engaged in.

The reactions of the engineering group were fundamentally different from those of the other groups. Here are some of the more interesting questions that were shared with us by the engineering group.

- "These are wonderful words: How do they help me be better educator?"

- "Knowing all of this is fine: How could it help me do better as an engineer? "

- "If engineering is taking action, doing and designing things, how does 
philosophy help me do it better? “

- "This is of great value and importance. We do not have anything like that in our curriculum, and it has worked well."

- "Do we really need to change anything in our education system? It seems to work. "

- "The engineering curriculum is based on skills, math, physics, and all of engineering concepts and practice. If we engage in pedagogical and philosophical discussions, reflections, and debates, it could reduce the students' engineering knowledge base. We would then develop weak students."

- "What would industry think? Would they still hire our graduates?

One year later one of the engineer faculty wrote the remarks shown in exhibit 3 in response to a question that I asked the participants, four of whom responded, three of whom were doctoral students.

I was pleased to participate in the weekly sessions on the philosophy of engineering education co-hosted by Mani Mina at ISU and John Heywood of Trinity College Dublin. I did not know what to expect during the meetings, but I wanted to participate because many of my educational interests are consistent with Mani's interests.

Since I did not know what to expect, it was necessary for me to acclimate myself to the sense of the meeting. John H was connected to us via Skype through Mani's laptop computer. Once this was connected, the meeting proceeded smoothly. Prior to the meeting we were to have read a document written by John and perhaps have watched a computer video recording of John reading his document. Because of my not having thought about the philosophy of engineering education very much before this, John's writing was a bit heavy for me and my eyelids. However, when I watched John reading the document, it became much more interesting. I did not fall asleep as I had done with the TV series "The Ascent of Man," and "Cosmos". At the beginning I was thinking that we may be discussing improved methods for educating the students, but very quickly it became clear that was not our objective. Our objective seemed to talk about quite a few things that did not directly relate to educating the students in the class room. The discussion more often centered upon the attitude of the person attempting to educate the students. I agreed with these things so I felt the discussion, by and large, did not change the way I felt about being an educator. (As an aside, for the first time, I have started weekly tutoring a ninth grade student in algebra. We will see if what rubbed off on me in the seminar series affects the way I handle the tutoring.)

While all the discussion was interesting, I never felt that we discussed anything that was directly going to change the direction of engineering education in the engineering community. It became clear to me that the intent was to change the attitude of the educator, and not deal directly with the teaching of the student. I am okay with this and I hope that John's and Mani's work leads to this.

With philosophical discussions, one does not suddenly jump up and say “Ah, Ha!.” Hence, there was not an immediate effect on me. What it did for me was to raise my awareness of many of the things involved in teaching that were beyond the classroom directly.

I wanted to learn more about people's thoughts for directly applying our topics to the classroom. The philosophy is well and good, but when the rubber meets the road, we need to apply the philosophy.

My personal feeling is that I can't take too much pure philosophy in teaching. I prefer the philosophy to accompany the applications of the same philosophy. That as the series of weekly sessions evolve, we go back and forth from "theory" to practice. I think the discussions both on philosophy and direct application would benefit from this.

Exhibit 3

Overall engineering participant's questions and concerns as expressed at the time could be summarized as- "These are nice words, and great perspectives, but how can I apply it to engineering and engineering education?" In a way, the engineering team was evidently looking for a summary and action items to help them with their teaching. 
To our surprise, the Physics, Math, and English participants did not have such questions. They tried to absorb, participate and contribute. At times they would seem to be bored and confused since in their opinion we were not getting deeper into the philosophical issues that would affect the pedagogical essence of engineering. One may think physics and engineering are close. But the physics members did not really ask the same type of questions and did not show the same concerns as those reflected in the above list. Generally the physics members were much more accepting of the content. My discussions with them after the series suggested that from their perspective they wanted more in depth philosophical studies and debates. At times they would ask "why are we not going more deeply into the epistemological issues of engineering education?" Why? We need to remember that physics is usually in the college of sciences and liberal studies and this field of study was historically called natural philosophy and only changed to Physics about the second half of the 19th century. Thus physics is likely to be closer to philosophical perspectives than engineering; however, the understanding of this observation needs more exploration.

As indicated, one year on, we asked some of the participants to provide us with their impressions about the class. One of them J. P. loved the activity but always had questions: "What should I do with this? What else do I need to know to implement these ideas." A year later his attitudes had changed as his comments in exhibit 4 show. Exhibit 5 shows the response from a doctoral student who came from a French speaking country. This student shows a deeper appreciation of the seminar. He was also one of the advocates of more of this type of activity. Exhibit 6 is another response from a graduate student in engineering who also came from a French speaking country. Exhibits 4 and 5 show more appreciation of the philosophical basis of discussion. We found out that in both their countries there had been a deper appreciation of philosophy in their education system as well the social structure they were brought up in.

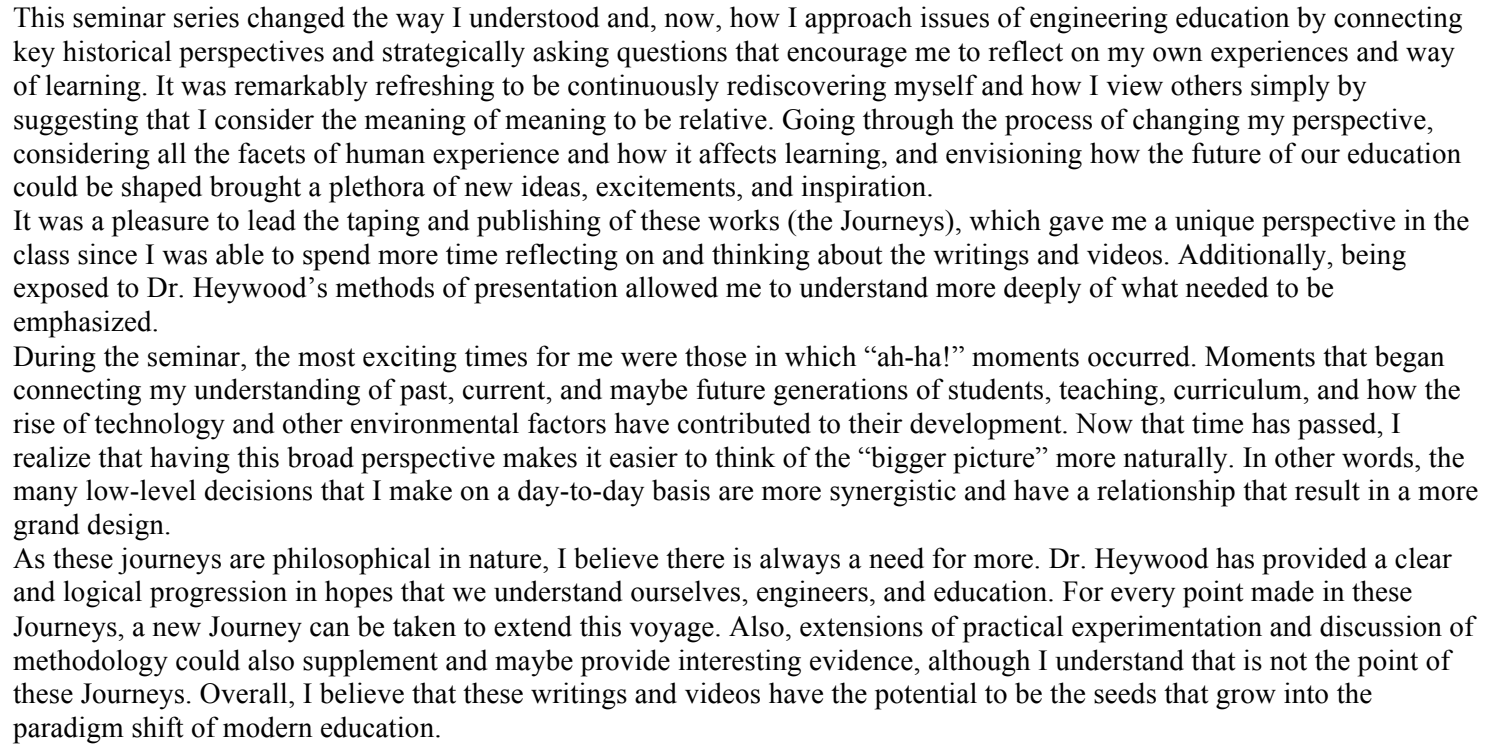
key historical perspectives and strategically asking questions that encourage me to reflect on my own experiences and way of learning. It was remarkably refreshing to be continuously rediscovering myself and how I view others simply by suggesting that I consider the meaning of meaning to be relative. Going through the process of changing my perspective, considering all the facets of human experience and how it affects learning, and envisioning how the future of our education could be shaped brought a plethora of new ideas, excitements, and inspiration.

It was a pleasure to lead the taping and publishing of these works (the Journeys), which gave me a unique perspective in the class since I was able to spend more time reflecting on and thinking about the writings and videos. Additionally, being exposed to Dr. Heywood's methods of presentation allowed me to understand more deeply of what needed to be emphasized.

During the seminar, the most exciting times for me were those in which "ah-ha!" moments occurred. Moments that began connecting my understanding of past, current, and maybe future generations of students, teaching, curriculum, and how the rise of technology and other environmental factors have contributed to their development. Now that time has passed, I realize that having this broad perspective makes it easier to think of the "bigger picture" more naturally. In other words, the many low-level decisions that I make on a day-to-day basis are more synergistic and have a relationship that result in a more grand design.

As these journeys are philosophical in nature, I believe there is always a need for more. Dr. Heywood has provided a clear and logical progression in hopes that we understand ourselves, engineers, and education. For every point made in these Journeys, a new Journey can be taken to extend this voyage. Also, extensions of practical experimentation and discussion of methodology could also supplement and maybe provide interesting evidence, although I understand that is not the point of these Journeys. Overall, I believe that these writings and videos have the potential to be the seeds that grow into the paradigm shift of modern education. 
"Few terms after taking the seminar, I was asked to write a reflection on how the seminar has affected my life. Here I am now "thinking about thinking" and despite the knowledge gained throughout the journeys I have realized that the world needs training in effective speaking. There is an essential need in the art of getting along in everyday business and social contacts. As I reverse the flow of time I see my own lack of finesse and understanding during the journeys (i.e.: Real or Imagined, From Perception to Self-Perception and a little Management en route...). During the course of the seminar, these journeys revealed that one's success is based upon the skill in human engineering to personality and the ability to lead people. It is my belief that the ideas or principles depending on viewer prospective conveyed in these journeys can literally revolutionize education and engineering.

Exhibit 5

"Thinking back at the seminar series, I am glad I took part in the class. My main purpose for participating was to gain new insights about education in general and I have learned a lot from the various discussions raised by the different participants. In addition I also believe that it was even more beneficial to me to just gain awareness of the problems in engineering education because that invites me to reflect more on the subject and to even consider solutions or at least potential improvements.

"I was also hoping that from learning more about education and learning theories I would be able to look more critically at the education system in my home country..... and I believe that the seminars have helped me get closer to that goal. I have been able to start identifying some of the problems associated with the educational system besides the lack of funds. I intend to keep on learning more about education and hopefully soon take it to the next step where I will be able to take positive action towards improving the educational system in ..... and other applicable third world countries."

Exhibit 6

\section{A need, a specter of something more (Mani Mina)}

The experiences and insights gained by participants seem to point toward a fundamental void in the engineering education community which seems to be a lack of dialog, creative discussion, and philosophical examination of what engineering is. Questions like- "why do we teach what we teach?" "What is needed?" "What should all engineering students know?" and many others are avoided. Answers to them lead to the foundation premises of engineering education. Currently some educators are challenging the prevailing premises yet there are few forums for such discussions that allow meaningful, visible and continuing dialog about engineering, engineering pedagogy, and philosophy of engineering as it relates to engineering education. The experience of the journeys shows that they were not only useful, but also very transformative on people's ways of thinking, perspectives, and vision. The reflections of a few of the participants (who kindly shared their ideas a year after the experience) supports this contention. All of them, in particular the ones involved in engineering, suggested the need for more such seminars, discussions, debate, and critiques that are regular rather than occasional which is not to say that the work of the ASEE divisions is unimportant. Neither do the journals as currently organized create a continuous dialogue. There is an opportunity for educational leaders to emerge.

\section{Discussion}

Recently there has been much interest in the integration of engineering with liberal education and the Liberal Education/Engineering in Society Division of ASEE has taken a lead in such discussions. An excellent example of integration is the model curriculum for schools described by the SCANS committee ${ }^{26}$. This committee had recommended that the US high 
school curriculum should develop five work place competencies resources, interpersonal, information, system and technology) together with three groups of foundation skills (basic, thinking and personal). While there is nothing controversial about the latter the idea that the former can be developed within subjects is contentious. A similar idea was put forward by the Enterprise in Higher Education Initiative (EHEI) in the UK in the $1990 \mathrm{~s}^{27}$. They thought that the skills of enterprise learning could be learnt within the normal subjects of study. It is true that project work and cooperative learning may develop some of these skills but they are undertaken without any formal knowledge of people and organizations (society). EHEI were opposed to bolt on courses. The course we have described is a bolt on course designed to function at Whitehead's level of romance that presents "The Human Side of Engineering". Although transdisciplinary we would argue that it is faithful to the integrity of the disciplines that it draws together and that it provides a step from which a participant can pursue one or more of the disciplines in depth. We have shown one of many ways of integrating the 'soft subject' content necessary for the proper pursuit of engineering and technological literacy in its many dimensions as illustrated in exhibit 1.

\section{References}

[1] Heywood, J (1973a). New Courses and Degree Structures. Committee on Higher Education, Council of Eurpoe. Strasbourg, Council of Europe.

[2] Heywood, J (1973b). American and English influences on the development of a transdisciplinary course on the technologist and society. Collected Papers of the ERM Division. Annual Conference of the American Society for Engineering Education. Iowa City. Pp 12- 29.

[3] Whitehead, A. N (1932). The Aims of Education and other Essays. London, Benn.

[4] Designing a stage of "romance" for programs in technological literacy. Proceedings American Society for Engineering Education (annual conference) AC 2014 - 8690

[5] Heywood, J (1989). Learning Adaptability and Change. The Challenge for Education and Industry. London, Paul Chapman.

[6] Heywood, J (2009). Managing and Leading Schools as Learning Organizations. Dublin, Original Writing for National Association of Principals and Deputies

[7] Ertas, A Maxwell, T., Rainey, V. P., and M. M. Tanik (2003). Transformation of higher education. The transdisciplinary approach to engineering. IEEE Transactions on Education, 46, (2), 289 -295.

[8] Kozmetsky, G (1997). Generational road maps and commercialization in science and technology. Journal of Integrated Design Process Science, 1, (1), 4 - 8.

[9] Woods, D. R (1994). Problem Based Learning. How to Gain the Most from PBL. Hamilton, Ontario, McMaster University Bookshop.

[10] Woods, D. R et al (1997). Developing problem solving skills with the McMaster problem solving program. Journal of Engineering Education, 86, (2), 75 - 92.

[11] Heywood, J et al (1966). The education of professional engineers for design and manufacture. (A model curriculum). Lancaster Studies in Higher Education. No 1, pp 2 - 151.

[12] loc. cit ref. 7. 
[13] Dyer, S and J. Schmalzel (1988). Micro-epectronics. Building the perfect beast. Proceedings Frontiers in Education Conference, 73 - 78.

[14] Heywood, J (2005). Engineering Education. Research and Development in Curriculum and Instruction. Hoboken, NJ. IEEE/Wiley.

[15] Fogarty, R (1993). Integrating the Curriculum. A Collection, Palatine, Il. IRI/Skylight Publ.

[16] Krupczak, J et al (2012). Defining engineering and technological literacy. Proceedings Annual Conference of the American Society for Engineering Education. Paper AC 2012-5100.

[17] ibid.

[18] Heywood, J (1986). Toward technological literacy in Ireland. An opportunity for an inclusive approach in J. Heywood and P. Matthews (eds) Technology, Society and the Curriculum. Practice and Theory in Europe. Roundthorn, Manchester. Pp $221-256$.

[19] Bucciarelli. L L (1994). Designing Engineers. Cambridge, MA. MIT Press.

[20] Bucciarelli, L. L (2003). Engineering Philosophy. Netherlands. Delft University Press.

[21] Heywood, J (1976). Engineers at work: An illuminative evaluation. The Vocational Aspect of Education. 28, (69), 25 - 38.

[22] Youngman, M. B, Oxtoby, R., Monk, J. D., and J. Heywood (1978). Analysing Jobs. Aldershot, Gower Press.

[23] Hutton, S. P. and P. Lawrence The work of production managers: Case studies of manufacturing companies in the United Kingdom, South Hampton, Department of mechanical engineering university of Southhapton 1982.

[24] Vinck, D (ed) (2003). Everyday Engineering. An Ethnography of Design and Innovation. Cambridge, MA. MIT Press.

[25] Trevelyan, J (2014). The Making of an Expert Engineer. London, Taylor and Francis (CRC Press).

[26] SCANS (1992). Learning a Living. A Blueprint for Higher Performance. Washington DC. US Department of Labour.

[27] Heywood, J (1994) Enterprise Learning and its Assessment. Technical report No 20. Learning Methods Branch. Sheffield. Employment Department 